\title{
Multivariate analysis for the classification and differentiation of Madeira wines according to main grape varieties
}

\author{
José S. Câmara $^{\mathrm{a}, *}$, M. Arminda Alves ${ }^{\mathrm{b}}$, José C. Marques ${ }^{\mathrm{a}}$ \\ ${ }^{a}$ Centro de Química da Madeira, Depto. de Química da Universidade da Madeira, Campus Universitário da Penteada, 9000-390 Funchal, Portugal \\ ${ }^{\mathrm{b}}$ Depto. de Enga Química, Faculdade de Engenharia da Universidade do Porto, Rua Roberto Frias, 4099 Porto, Portugal
}

Received 9 March 2005; received in revised form 2 July 2005; accepted 4 August 2005

Available online 9 September 2005

\begin{abstract}
In order to differentiate and characterize Madeira wines according to main grape varieties, the volatile composition (higher alcohols, fatty acids, ethyl esters and carbonyl compounds) was determined for 36 monovarietal Madeira wine samples elaborated from Boal, Malvazia, Sercial and Verdelho white grape varieties. The study was carried out by headspace solid-phase microextraction technique (HS-SPME), in dynamic mode, coupled with gas chromatography-mass spectrometry (GC-MS). Corrected peak area data for 42 analytes from the above mentioned chemical groups was used for statistical purposes. Principal component analysis (PCA) was applied in order to determine the main sources of variability present in the data sets and to establish the relation between samples (objects) and volatile compounds (variables). The data obtained by GC-MS shows that the most important contributions to the differentiation of Boal wines are benzyl alcohol and (E)-hex-3en-1-ol. Ethyl octadecanoate, (Z)-hex-3-en-1-ol and benzoic acid are the major contributions in Malvazia wines and 2-methylpropan-1-ol is associated to Sercial wines. Verdelho wines are most correlated with 5-(ethoxymethyl)-furfural, nonanone and cis-9-ethyldecenoate. A 96.4\% of prediction ability was obtained by the application of stepwise linear discriminant analysis (SLDA) using the 19 variables that maximise the variance of the initial data set.
\end{abstract}

(C) 2005 Elsevier B.V. All rights reserved.

Keywords: Wine; Volatile compounds; HS-SPME/GC-MS analysis; PCA; SLDA

\section{Introduction}

Madeira wines are characterized by a typical vinification and ageing procedures, including fortification in order to obtain an ethanol content of about $18 \%(\mathrm{v} / \mathrm{v})$, followed by a baking process known as "estufagem" during which the wine is submitted to rather high temperatures $\left(45-50^{\circ} \mathrm{C}\right)$ for about three months. The four basic types of Madeira wines are named according the main grape varieties from which they are prepared. Malvazia is fortified in an early stage of fermentation in order to produce a distinctive sweet wine with a sugar content of approximately $110 \mathrm{gl}^{-1}$. Boal is fortified in order to obtain a medium sweet wine $\left(90 \mathrm{gl}^{-1}\right)$ and the Verdelho ferments still further to produce a medium dry wine

\footnotetext{
* Corresponding author. Tel.: +351 291705112; fax: +351 291705149 .

E-mail address: jsc@uma.pt (J.S. Câmara).
}

( $65 \mathrm{~g}^{-1}$ of sugar). Sercial is allowed to complete fermentation and originates dry wines with less than $25 \mathrm{~g}^{-1}$ of sugar content. The baking process plays an important role in the definition of the bouquet, as the temperature can change the chemical profile and, consequently, the organoleptic character of the wines, by the increase of the kinetics of chemical and enzymatic reactions occurring during wine conservation, such as it happens with other foods and beverages [1-5]. In addition, it must be noted that old Madeira wines are maintained for long periods of aging, frequently more than 20 years, in cellars which temperatures as high as $30-35^{\circ} \mathrm{C}$ and humidity levels of $70-75 \%$. The quality and value of the wine is closely related with the characteristic aroma developed during this long maturation period.

The aroma is one of the most important factors in the determination of wine character and quality. The volatile fraction of a wine can be composed by over 800 different compounds 
$[6,7]$ but only some tens are odour-active [8,9] and must be considered for differentiation purposes. These compounds belong to very heterogeneous groups such as monoterpenes, higher alcohols, aldehydes, ketones, ethyl esters and fatty acids. Some of these compounds come from the grapes and are typical of the variety, but most of them are formed during fermentation process and wine ageing. This great variety of volatile compounds, with different polarities, volatilities and a wide range of concentrations, is responsible for the complexity of wine bouquet and ensures the specificity and character.

The wine aroma composition is influenced by many factors such as grape variety, edafoclimatic conditions and winemaking process but also depends on yeast strain used, $\mathrm{pH}$ of the medium, content and type of nitrogen available, sugars, fermentation temperature and aeration. Each one of these parameters has a significant influence on the quality of the wine and affects the characterisation and differentiation of different wines.

Wine production is actually spread all over the world and brand names and processes are sometimes subject of adulteration or reproduction, increasing the demand for quality studies and authenticity investigation [10]. Identification of wine aroma components and the relationships between their relative content may be a useful tool in differentiating the wines from different varieties and establishing criteria of genuineness to improve the quality of the wines, prevent fraud and guarantee their origin. In general, analysis of volatile compounds can be used to characterise different varieties such as the contribution of ethyl esters of fatty acids and acetates of higher alcohols, from neutral grape varieties [11]. Moreover, volatile wine compounds can be used to differentiate wines with different geographic origins [12]. Kwan and Kowalski [13] performed a good differentiation of samples from French and American Pinot Noir on the basis of hexan1-ol and cyclo-hexane. García-Jares et al. [14] differentiate white wines from Rias Baixas (Spain) using 19 volatile compounds. Sugars, organic acids and amino acids were used by Arminda Alves [15] in the differentiation of Porto wines and Guedes de Pinho used the multivariate technique for characterisation and differentiation varieties from different regions [16]). Trace elements were used by Day et al. [17] for the identification of the geographical origin of wines using stepwise discriminant analysis. Despite the work carried out on this area, the performance achieved is always dependent on the data set available as some components are present in high concentration (hundreds of $\mathrm{mg} \mathrm{l}^{-1}$ ) and can be easily analysed by GC but the majority is found at the low $\mathrm{ng}^{-1}$ level and need to be extracted and concentrated before analysis. In addition, major compounds from the complex wine matrix can cause interference increasing the difficulty of analysis of trace compounds.

Several classical analytical methods such as liquid-liquid extraction [18,19], simultaneous distillation-solvent extraction [20], solid-phase extraction [21,22], supercritical fluid extraction [23], microwave extraction [24] and ultrasound extraction [25], have been developed for the analysis of the minor volatile compounds in wines. These classical analytical methods have some drawbacks such as the relatively low reproducibility, possibility of solvent cross-contamination, insufficient selectivity and time consuming procedures. At the beginning of the 1990s a new technique, solid-phase micro-extraction (SPME), was proposed by Pawliszyn and coworkers [26,27] offering two main advantages: no extraction solvent required and combination of extraction and pre-concentration in a single step without pre-treatment of samples. Moreover, the procedure showed to be fast, inexpensive, requiring low sample volumes and good automation. This technique has been successfully used in wine samples [28-31] to characterise a wide range of aroma compounds, including monoterpenes and $\mathrm{C}_{13}$ norisoprenoids [32], esters [33] and sulphides [34].

Grape variety, vintage year and winery procedures are the three main sources of variation in the chemical composition of wine. Although the main purpose of this study was to determine which components could differentiate Madeira wines according variety, an attempt was made to determine whether the variables selected for this purpose could also reveal other sources of differentiation such as the harvesting year. To achieve this objective, the content of higher alcohols, acetates, fatty acids, ethyl esters and carbonyl compounds of 36 monovarietal Madeira wines samples produced from the four white grape varieties Boal, Malvazia, Sercial and Verdelho, was determined over three consecutive harvests (1998-2000). Multivariate techniques of data analysis - principal component analysis (PCA) and stepwise linear discriminant analysis (SLDA) - were employed in order to establish differentiation criteria as a function of the varieties used in the preparation of these wines.

The analytes were extracted by HS-SPME using a polyacrylate fibre (PA-85 $\mu \mathrm{m})$ and analysed by GC-MS. The influence of climatic conditions and winemaking techniques on the differentiation of wine varieties was not considered in the study as grapes had been harvested in the same site and the same technology was applied for all wines.

\section{Materials and methods}

\subsection{Sample wines}

Grapes of Vitis vinifera cultivars Boal, Malvazia, Sercial and Verdelho, supplied for the Instituto do Vinho Madeira (IVM), collected at the final stage of ripening were used. Production techniques were similar to all wines studied, with the exception of the fermentation period before fortification. The musts were treated with $\mathrm{SO}_{2}\left(50 \mathrm{mg} \mathrm{l}^{-1}\right)$ and fermentation, carried out in oak casks with spontaneous yeasts, was stopped by addition of ethanol when the appropriate amount of natural grape sugars has been converted. The 36 wines stayed in casks for eight months before sample collection 
and storage at $-28{ }^{\circ} \mathrm{C}$ until use. The HS-SPME extraction was always carried out in triplicate.

\subsection{Sample extraction conditions}

Volatile wine compounds were extracted by headspace solid-phase micro-extraction (HS-SPME) after optimisation of the major parameters with influence in the extraction process [32,35]: fibre type, time and temperature of adsorption, ionic strength and $\mathrm{pH}$. Optimal conditions of extraction were obtained using the following procedure: $2.4 \mathrm{ml}$ of wine were transferred to a $4 \mathrm{ml}$ vial (headspace volume was $1.6 \mathrm{ml}$, according to the phase ratio $1 / \beta=0.6$ ) [36], the ionic strength was adjusted to $30 \%$ with $\mathrm{NaCl}$ and the $\mathrm{pH}$ was maintained at $3.3-3.5$ ( $\mathrm{pH}$ of the wine). The samples $(50 \mathrm{ml})$ were spiked with $0.422 \mu \mathrm{g} \mathrm{I}^{-1}$ of octan-3-ol (Sigma-Aldrich) as internal standard, by addition of $50 \mu l$ of alcoholic solution at $422 \mathrm{mg}^{-1}$. The vial was sealed and headspace extraction was performed for $120 \mathrm{~min}$ at $40^{\circ} \mathrm{C}$ with a $85 \mu \mathrm{m}$ PA fibre, keeping the sample under continuous stirring (1200 rpm). The fibre was maintained in the GC injector for $5 \mathrm{~min}$ for complete desorption.

\subsection{GC-MS conditions}

The wine extracts were analysed by gas chromatography coupled with mass spectrometry (GC-MS) using a Varian STAR 3400Cx series II gas chromatograph, equipped with a $30 \mathrm{~m} \times 0.25 \mathrm{~mm}$ i.d., $0.25 \mu \mathrm{m}$ film thickness, Stabilwax (JW Scientific) fused silica capillary column, connected to a Varian Saturn III mass selective detector and operated according to the method described by Câmara et al. [32]. Splitless injection mode was used. The initial oven temperature was set to $40^{\circ} \mathrm{C}$ for $1 \mathrm{~min}$. The temperature was increased in three steps: $40-120^{\circ} \mathrm{C}$, at $1^{\circ} \mathrm{min}^{-1} ; 120-180^{\circ} \mathrm{C}$ at $1.7^{\circ} \mathrm{C} \mathrm{min}{ }^{-1}$ and $180-220^{\circ} \mathrm{C}$, at $25^{\circ} \mathrm{C} \mathrm{min}^{-1}$. Each step was preceded by a small period at constant temperature of 2,1 and $10 \mathrm{~min}$, respectively. The injector temperature was $250^{\circ} \mathrm{C}$ and the transfer line was held at $220^{\circ} \mathrm{C}$. Mass spectra were recorded after electronic impact (EI) ionisation at $70 \mathrm{eV}$. The mass-tocharge ratio range $(\mathrm{m} / \mathrm{z})$ used was 30-300 $\left(1.9\right.$ spectra $\left.^{-1}\right)$. The ion source and mass ion trap temperatures were set to $180^{\circ} \mathrm{C}$.

\subsection{Statistical analysis}

Significant differences among the four Madeira wines varieties for each of the constituents were determined by one-way analysis of variance (Anova) using a SPSS Program, version 11.0 (SPSS Inc., 2003). Principal component analysis and stepwise linear discriminant analysis were performed using the same SPSS program. These techniques were applied to the normalized relative amounts of the volatile compounds.

Principal component analysis is an unsupervised technique that reduces the dimensionality of the original data matrix retaining the maximum amount of variability [37], allowing the visualisation of the different wines in a two dimensional space and identifying the directions in which most of the information is retained. It is therefore possible to explain the differences between various wines by means of factors obtained from the data sets and, at the same time, to determine which variables contribute the most for such differences.

Stepwise linear discriminant analysis is a supervised method used for classification purposes. SLDA renders a number of orthogonal linear discriminant functions equal to the number of categories minus one. This method minimises the variance within categories and maximises the variance between categories [38]. The variables included in the analysis are determined with a stepwise-LDA using a Wilk's Lambda as a selection criterion and an $F$-statistic factor to establish the significance of the changes in Lambda when a new variable is tested. The prediction capacity of the discriminant models was studied by "cross validation" in order to determine the stability of the model.

\section{Results and discussion}

The HS-SPME/GC-MS method developed was found to be fully suitable for the analysis of volatile compounds in wine due to its selectivity and sensitivity. A total ion current (TIC) chromatogram obtained for a Malvazia wine sample with the $85 \mu \mathrm{m}$ fibre at the optimal extraction conditions [31], can be seen in Fig. 1. Careful analysis of the chromatograms allowed the assignment of clearly different mass spectra for about eighty peaks (Table 1). The compounds were identified by comparison with mass spectra obtained from the sample with those from pure commercially available standards injected in the same conditions, by comparing the Kovats indexes and the mass spectra included in the NIST library.

The average values from three consecutive harvests showed that these wines have characteristic profiles. Higher alcohols, fatty acids and ethyl esters are the major groups in all studied varieties. Boal wines are characterised by the highest content of $\mathrm{C}_{13}$ norisoprenoids, higher alcohols and carbonyl compounds. Malvazia wines show the highest concentrations of monoterpenes. Sercial wines present important levels of acetates, fatty acids and ethyl esters and the highest content of fix acids and phenols while Verdelho wines are characterised by the highest content of ethyl esters and furan compounds. Fig. 2 shows the relative amount of total free fraction for each chemical group in the Madeira wines under study.

The compounds clearly identified were used for statistical treatments. All statistical treatments were performed on corrected peak area data (peak area/internal standard area).

\subsection{Principal component analysis (PCA)}

The 42 analytical variables used for statistical purposes were gathered into four different groups (Table 2): higher 


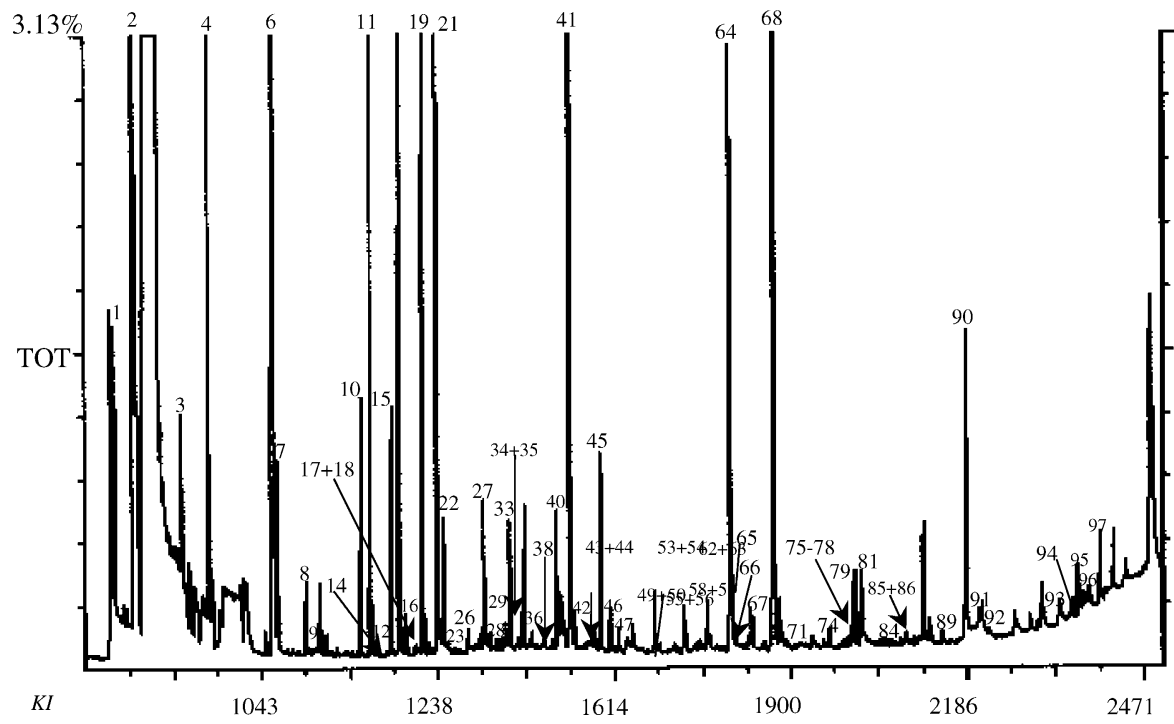

Fig. 1. Typical total ion current (TIC) chromatogram of a Malvazia wine sample obtained by HS-SPME/GC-MS using a $85 \mu \mathrm{m}$ PA fibre. Identified analytes are listed in Table 1 (KI: Kováts Indice).

alcohols, fatty acids, ethyl esters and carbonyl compounds. Principal component analysis from data matrix was then performed in each one of the different groups in order to find the main sources of variability and to establish the relation between varieties and volatile compounds. Although the best procedure is to analyse all variables at the same time, we choose to subdivide the compounds into several groups of variables for the consistency of the results, maintaining the number of cases equal or higher than the number of variables.

\subsection{Higher alcohols}

When higher alcohols were analysed by PCA, a clear differentiation among varieties was found. No apparent differentiation was observed when considering the harvesting year.

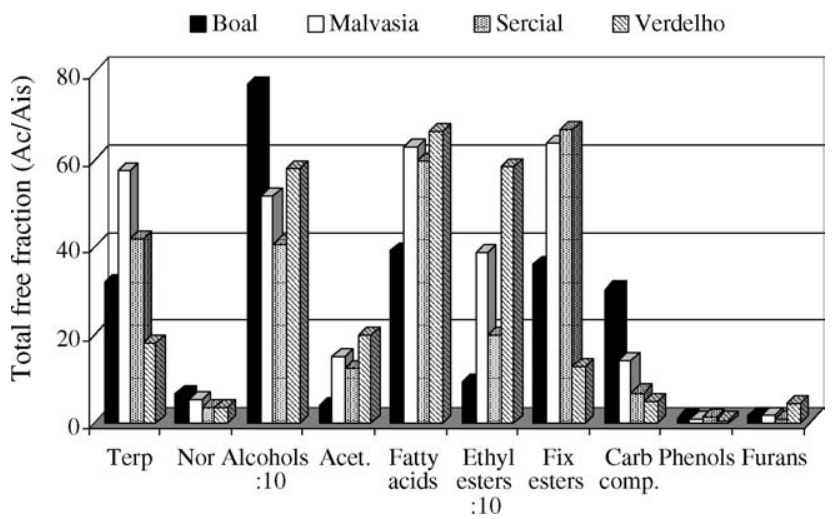

Fig. 2. Total free fraction (Ac/Ais: compound area/internal standard area) for the chemical groups studied (Terp: monoterpenes; Nor: $\mathrm{C}_{13}$ norisoprenoids; Alcohols: higher alcohols; Acet.: acetates; Carb comp.: carbonyl compounds).
Applying PCA to the normalized relative amounts of the 11 analytical variables (higher alcohols) and 36 objects (wines), two factors were extracted explaining $81.2 \%$ of the total variance of initial data set. The observation of the loading scores suggests that two variables, having coefficients magnitude $<0.8$ - propan-1-ol and 3-methylbutan-1-ol - are insufficient to adequately describe the samples according to variety, and were removed from the matrix. The new set (data matrix $36 \times 9$ ) account for $87.9 \%$ of the total variance in the data. The first principal component (PC1) explains $62.2 \%$ of the variance in the initial data set and the second principal component (PC2) explain $25.7 \%$. The eigenvalues, percentage of variance and the cumulative percentage explained by the two first principal components are showed in Table 3.

The projections of the samples along the directions identified by the first two PC's, is reported in Fig. 3a where the first principal component $(\mathrm{PC} 1)$ of wine samples is plotted against the second principal component (PC2). The separation of the different categories of wine samples from this PC1-PC2 scatter point plot is obvious. This figure shows that wines from Malvazia, Sercial and Verdelho varieties were separated by the second principal component, while wines from Boal variety are most influenced by the variables related with the first PC.

The coefficient that defines the weight of the original variable in the PC's can be investigated to understand which chemical compounds are responsible for the ranking of wines. Benzyl alcohol (0.98), 2-phenylethanol (0.95), butan-1-ol $(0.92)$ and $(E)$-hex-3-en-1-ol (0.90) were highly loaded on the first PC, while (Z)-hex-3-en-1-ol (0.92) and (E)-hex-2-en1-ol (0.91) were loaded on the second PC explaining most of the variability. Hexan-1-ol $(0.81 ; 0.53)$ is important on both PC1 and PC2 components. Fig. 3 shows the corresponding loadings plot that establishes the relative importance of each 

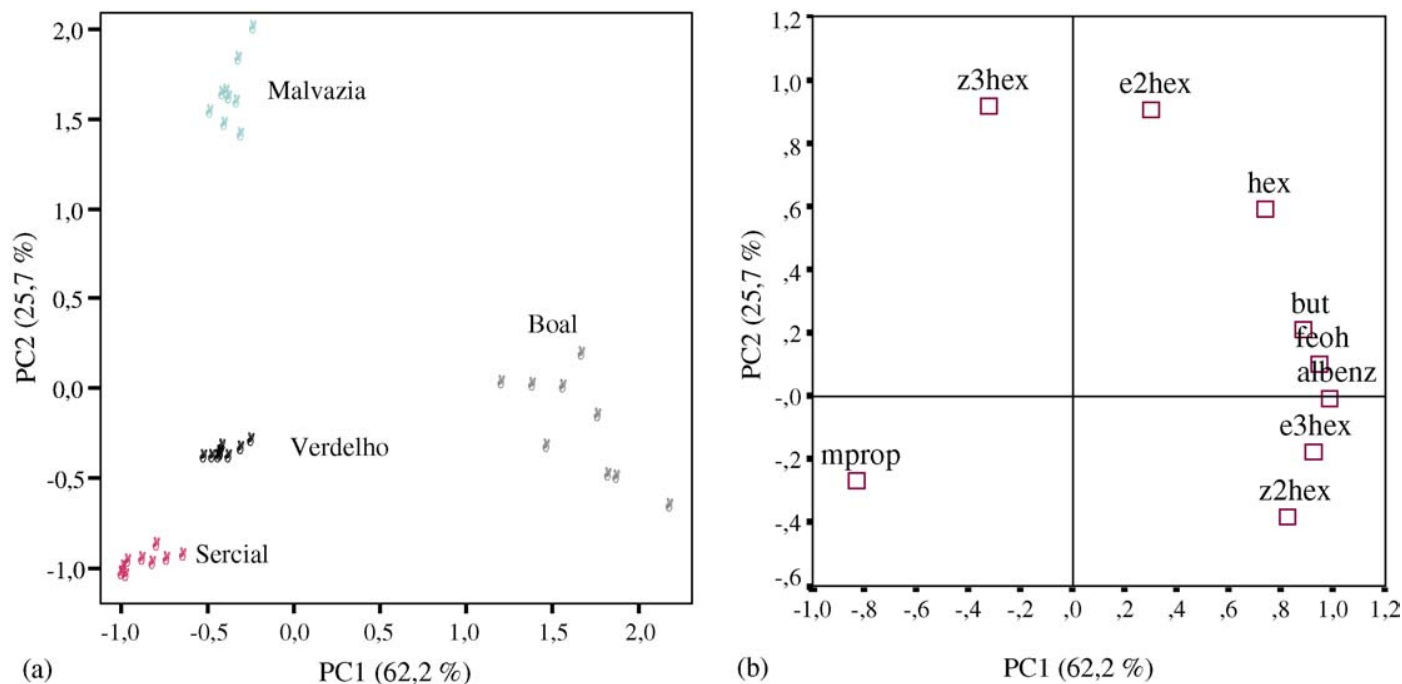

Fig. 3. PC1 vs. PC2 scatter plot of the main sources of variability between the Madeira wines (a) distinction between the samples (scores) and (b) relation between the nine higher alcohols (loadings).

variable and it is therefore useful for the study of relations among the higher alcohols and between variables and wines.

The wines from varieties Sercial and Verdelho are located in the third quadrant (negative PC1 and PC2). Only 2methylpropan-1-ol $(-0.86)$ is in accordance with this requisite. These wines show low values of $(Z$ )-hex-3-en-1-ol and $(E)$-hex-2-en-1-ol and very low values of hexan-1-ol and all other variables influencing positively the first PC. Malvazia wines are located in the second quadrant (negative PC1 and positive PC2). (Z)-Hex-3-en-1-ol (-0.32; 0.92) and $(E)$-hex-2-en-1-ol $(0.77 ; 0.49)$ are strongly associated with this quadrant. Boal wines are essentially represented in the fourth quadrant (positive PC1 and negative PC2). Benzyl alcohol $(0.98 ;-0.12)$, 2-phenylethanol $(0.95 ;-0.02)$, butan-1-ol $(0.92 ; 0.09),(E)$-hex-3-en-1-ol $(0.92 ;-0.18)$ and

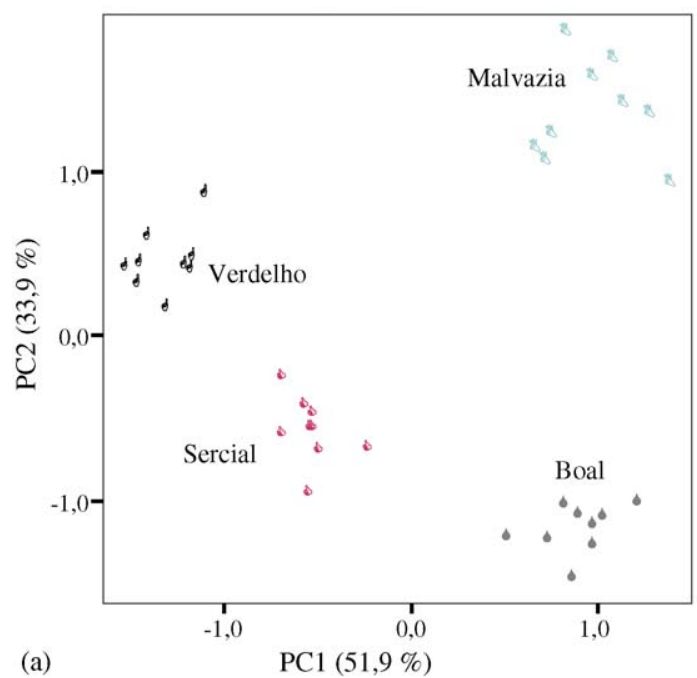

(Z)-hex-2-en-1-ol $(0.83 ;-0.38)$ are the variables related with these wines (Fig. 3b). They are characterized by low values of 2-methylpropan-1-ol $(-0.86 ;-0.20)$.

\subsection{Fatty acids}

The 13 variables from the initial data matrix of fatty acids (Table 2) explained $66.8 \%$ of the variance. The redundant variables not contributing to the explanation of total variance (coefficients magnitude $<0.8$ ) were removed from the data set. PCA showed a clear separation of wines according to varieties when a data matrix $(36 \times 6)$ with the fatty acids propionic, hexanoic, octanoic, 2-hydroxybenzenepropionic, 2-ethyl-hexanoic and benzoic - is used. The first two principal components accounted for $85.8 \%$ of the total variance of

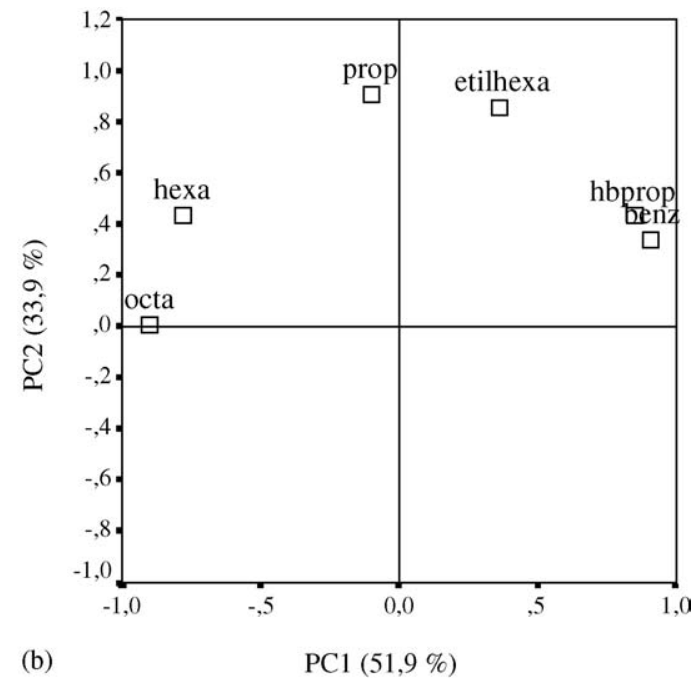

Fig. 4. PC1 vs. PC2 scatter plot of the main sources of variability between the Madeira wines (a) distinction between the samples (scores) and (b) relation between the six fatty acids (loadings). 
Table 1

Volatile compounds identified in Malvazia wines

\begin{tabular}{cl}
\hline Terpenes & trans-Linalool oxide \\
20 & cis-Linalool oxide \\
23 & Unknown $1(93+121+136)$ \\
26 & Linalool \\
33 & 2,6-Dymethylocta-1,7-dien-3,6-diol \\
38 & $\alpha$-Terpineol \\
47 & $(+)$ - - -Cadinene \\
55 & Citronellol \\
57 & Unknown $2(93+121+136)$ \\
59 & Geraniol \\
66 & Nerolidol \\
86 & Farnesol \\
91 & \\
$C_{13}$ norisoprenoids & \\
288 & Vitispirane I \\
29 & Vitispirane II \\
48 & Unknown 3 $(177+192)$ \\
52 & TDN \\
63 & $\beta$-Damascenone
\end{tabular}

Higher alcohols

$\begin{aligned} 3 & \text { Butan-1-ol } \\ 5 & \text { 4-Methylpentan-2-ol } \\ 6 & \text { 2-Methylbutan-1-ol } \\ 11 & \text { Hexan-1-ol } \\ 12 & \text { (E)-Hex-3-en-1-ol } \\ 15 & (Z) \text {-Hex-3-en-1-ol } \\ 16 & (E) \text {-Hex-2-en-1-ol } \\ 17 & \text { (Z)-Hex-2-en-1-ol } \\ 32 & \text { Butan-1,3-diol } \\ 34 & \text { Nonan-1-ol } \\ 50 & \text { 3-Methyltio-propan-1-ol } \\ 67 & \text { Benzyl alcohol } \\ 68 & \text { 2-Phenylethanol } \\ 84 & \text { 2-Phenoxyethanol } \\ & \\ 4 & \\ 4 & \text { 3-Methylbutyl acetate } \\ 62 & \text { Hexyl acetate } \\ & \text { 2-Phenylethyl acetate }\end{aligned}$

Fatty acids

21
31
35
40
44
49
65
71
81
83
91
93
95
99

Ethyl esters

$\begin{aligned} 2 & \text { Ethyl acetate } \\ 7 & \text { Ethyl hexanoate } \\ 19 & \text { Ethyl octanoate } \\ 30 & \text { Ethyl nonanoate } \\ 41 & \text { Ethyl decanoate } \\ 42 & \text { Ethyl benzoate } \\ 46 & \text { Ethyl cis-9-decenoate } \\ 58 & \text { Ethyl benzeneacetate }\end{aligned}$

Table 1 (Continued)

\begin{tabular}{|c|c|}
\hline 64 & Ethyl dodecanoate \\
\hline 79 & Ethyl tetradecanoate \\
\hline 90 & Ethyl hexadecanoate \\
\hline 97 & Methyl-7,10-octadecadienoate \\
\hline \multicolumn{2}{|c|}{ Ethyl esters of fix acids } \\
\hline 9 & Ethyl 2-oxopropanoate \\
\hline 10 & Ethyl lactate \\
\hline 18 & Ethyl 2-hydroxy-3-methylbutanoate \\
\hline 25 & Ethyl 2-hydroxypropanoate \\
\hline 45 & Diethyl succinate \\
\hline 76 & Isopropyl miristate \\
\hline 78 & Ethyl 3-hydroxyhexanoate \\
\hline \multicolumn{2}{|c|}{ Carbonyl compounds } \\
\hline 1 & Acetaldehyde \\
\hline 27 & Benzaldehyde \\
\hline 94 & 1-(2-Methylphenyil)ethanone \\
\hline \multicolumn{2}{|l|}{ Phenols } \\
\hline 56 & Methyl salicilate \\
\hline 75 & 4-Ethyl-2-methoxyphenol \\
\hline 77 & (1,1-Dimethylethyl)-2-methoxyphenol \\
\hline 88 & Eugenol \\
\hline \multicolumn{2}{|l|}{ Furans } \\
\hline 22 & Furfural \\
\hline 87 & 5-(Acetoxymethyl)furfural \\
\hline 96 & 5-(Hydroxymethyl)furfural \\
\hline 69 & pantolactone \\
\hline 53 & $\gamma$-Butyrolactone \\
\hline \multicolumn{2}{|l|}{ Others } \\
\hline 43 & Non-1-ene \\
\hline 51 & Non-3-ine \\
\hline 73 & 1,3-Dymethylnaphtalene \\
\hline 89 & 1,6-Dimethyl-4-(1-methylethyl)-naphtalene \\
\hline
\end{tabular}

the initial data set. Table 3 present the eigenvalues, cumulative percentage and total variance explained by the two first principal components. The first component explains $51.9 \%$ of the variability in the initial data set and the second component explains $33.9 \%$.

In Fig. 4a, the first principal component (PC1) is plotted against the second principal component (PC2). The separation among different categories of wine samples from this PC1-PC2 scatter point plot is obvious. Fig. 4b shows the corresponding loadings plot that establishes the relative importance of each variable and it is therefore useful for the study of relations among the acids compounds and relations between fatty acids and wines.

The variables with the highest contribution to the first component, explaining $51.9 \%$ of total variance of data set, are benzoic acid (0.91), octanoic acid $(-0.89)$, 2hydroxybenzenepropionic acid (0.85) and, in minor extent, hexanoic acid $(-0.78)$. The second principal component (33.9\% of total variability) is strongly correlated with propionic acid (0.91) and 2-ethyl-hexanoic acid (0.85) (Fig. 4b).

From the plot of the 36 wines on the plane defined by these first two principal components, the wines Malvazia appear on the first quadrant. These samples are characterized by the variables associated to positive values of the 
Table 2

Identification of the 42 variables used in the multivariate analysis

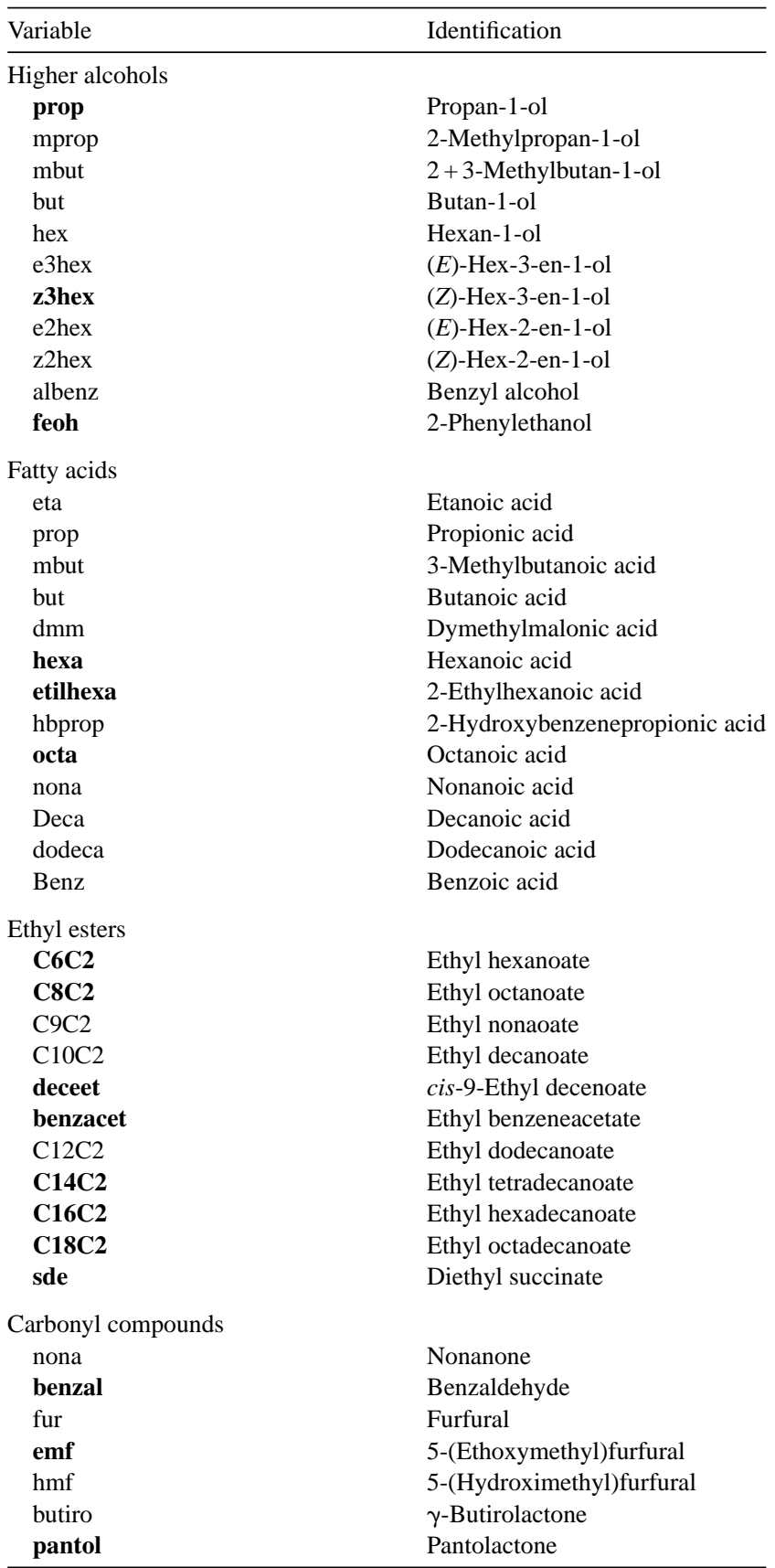

The variables used in the SLDA are indicated in bold.

two first principal components being characterized, primarily, by benzoic acid $(0.91 ; 0.33)$ and in minor extent by 2-hydroxybenzenepropionic acid $(0.85 ; 0.43)$ and 2-ethylhexanoic acid $(0.36 ; 0.85)$. Propionic acid $(0.91 ;-0.10)$, octanoic acid $(-0.89 ; 0.01)$ and hexanoic acid $(-0.78 ; 0.43)$, are the characteristic variables for Verdelho wines (negative PC1 and positive PC2).

Sercial and Boal samples are represented in the third (negative $\mathrm{PC} 1$ and $\mathrm{PC} 2$ ) and fourth (positive $\mathrm{PC} 1$ and negative PC2) quadrants, respectively. The first PC explains the separation from Sercial and Verdelho wines to Boal and Malvazia wines, while the second PC separated Sercial and Boal wines from Verdelho and Malvazia wines (Fig. 4a).

\subsection{Ethyl esters}

Principal component analysis from the data matrix $(36 \times 10)$ built with ethyl esters, was also performed. It was observed that $91.0 \%$ of the total variance of these compounds could be explained by the first two principal components (Table 3). The first principal component, explaining $51.8 \%$ of the variance, is mainly associated with ethyl octadecanoate (0.95), ethyl tetradecanoate (0.95) ethyl benzeneacetate (0.88), while ethyl octadecanoate $(0.98)$, cis-9ethyldecenoate (0.97) and ethyl hexanoate (0.95) contribute in great extent to the second principal component, explaining $39.2 \%$ of the total variance (Fig. 5a).

From the plot of the 36 wines on the plane defined by these first two principal components, the Malvazia wines appear on the right side of the plane, grouped by variety, while wines of varieties Boal, Sercial and Verdelho are found on the left side of the plane (Fig. 5b).

Verdelho wines are characterized by the variables contributing with positive values to $\mathrm{PC} 2$ and negative to PC1. Thus cis-9-ethyldecenoate $(-0.11 ; 0.97)$ and ethyl hexanoate $(-0.19 ; 0.95)$, are the major contributions to the differentiation of Verdelho from other types of Madeira wines. Sercial and Boal wines are contained in the third quadrant (negative values for PC1 and PC2). Ethyl octadecanoate (0.95; $0.23)$, ethyl benzeneacetate $(0.88 ;-0.32)$, ethyl hexadecanoate $(0.86 ; 0.31)$ and diethyl succinate $(0.84 ;-0.51)$, are strongly associated to Malvazia wines.

\subsection{Carbonyl compounds}

Applying the principal component analysis to the data matrix $(36 \times 7)$ built with the seven variables of carbonyl compounds, two principal components were extracted explaining $87.1 \%$ of the total variability. The variables strongly associated with the first component, 5-(ethoxymethyl) furfural (0.99), nonanone (0.98) and 5-(hydroxymethyl) furfural (0.96), explain $45.9 \%$ of the variability in the initial data set. The second component explained $41.2 \%$ and is mainly associated with $\gamma$-butyrolactone $(0.98)$ and furfural (0.89). The eigenvalues, percentage of variance and cumulative percentage explained by the two first principal components for carbonyl compounds are presented in Table 3 .

Fig. 6a shows the scores scatter plot on the two first principal components, representing the differences among the 36 wine samples. Fig. $6 \mathrm{~b}$ represents the corresponding loadings plot that establishes the relative importance of each carbonyl compounds, and is therefore useful for the study of relations among the carbonyl compounds and the relations between carbonyl compounds and samples.

The second quadrant contains the Boal wines. These samples are characterized by the variables associated to positive values of the second principal component mainly benzalde- 
Table 3

Eigenvalues, percentage of variance and cumulative percentage explained by the two principal components for each chemical group under study

\begin{tabular}{|c|c|c|c|c|}
\hline \multirow[t]{2}{*}{ Group } & \multirow[t]{2}{*}{ Principal component } & \multirow[t]{2}{*}{ Eigenvalue } & \multicolumn{2}{|c|}{ Rotation sums of squared } \\
\hline & & & Variance $(\%)$ & Cumulative (\%) \\
\hline \multirow[t]{2}{*}{ Higher alcohols } & 1 & 5.657 & 62.231 & 62.231 \\
\hline & 2 & 2.317 & 25.744 & 87.975 \\
\hline \multirow[t]{2}{*}{ Fatty acids } & 1 & 3.112 & 51.859 & 51.859 \\
\hline & 2 & 2.038 & 33.969 & 85.828 \\
\hline \multirow[t]{2}{*}{ Ethyl esters } & 1 & 5.179 & 51.787 & 51.787 \\
\hline & 2 & 3.921 & 39.214 & 91.001 \\
\hline \multirow[t]{2}{*}{ Carbonyl compounds } & 1 & 3.212 & 45.881 & 45.881 \\
\hline & 2 & 2.886 & 41.230 & 87.111 \\
\hline
\end{tabular}

The bold values are indicative of the total percentage explained by the two first principal components.

hyde $(-0.41 ; 0.89)$. The third quadrant contains the Malvazia and Sercial wines (negative PC1 and PC2). There is no carbonyl compounds associated with this quadrant.

Verdelho samples are represented in fourth quadrant (positive PC1 and negative PC2). 5-(Ethoxymethyl) furfural (0.99; $0.04)$, nonanone $(0.98 ; 0.05)$ and 5-(hydroxymethyl) furfural $(0.96 ;-0.05)$ are the variables most related with this wine variety.

\subsection{Stepwise linear discriminant analysis (LDA)}

After PCA, a linear discriminant analysis was applied to look at the most useful variables in the differentiation between wines and to find discrimination functions for the classification of new samples in the correct group. This parametric method is widely used for classification purposes. The classification was performed according to wine variety: Boal, Malvazia, Sercial and Verdelho. Two statistically significant discriminant functions were obtained, explaining $98.5 \%$ of the variability. The variables: (Z)-hex-3-en-1-ol and diethyl succinate (first root-92.9\%) and 5-(ethoxymethyl)furfural, ethyl octanoate and hexanoic acid (second root-5.6\%), had the highest $F$-value, so they were the most important variables for the differentiation of the wines from these four varieties.

The prediction capacity of the SLDA model was evaluated by "leave-one-out" cross validation. During this cross validation test, ungrouped cases are removed from the initial matrix of data. The classification model is rebuilt and the cases removed are classified in this new model. Table 4 summarises the results of the classification matrix of the obtained SLDA model, obtained for all the samples and separated for variety, showing an average classification of $96.4 \%$, meaning that $7 / 8$ of the objects were correctly classified (Table 4). All Madeira wines studied showed high percentage of correctly classified cases, almost $100 \%$ in the case of Malvazia and Verdelho wines. Then the results can be considered satisfactory and acceptable and the selected variables are useful to
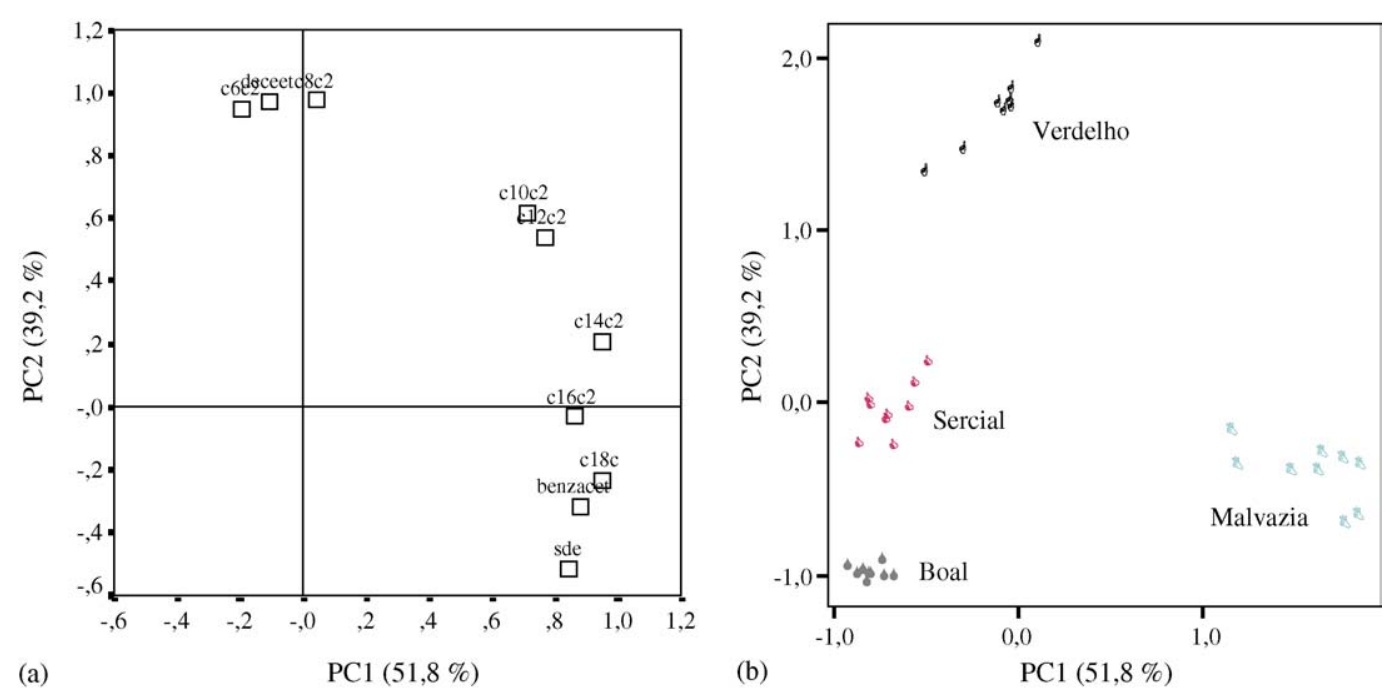

Fig. 5. PC1 vs. PC2 scatter plot of the main sources of variability between the Madeira wines (a) relation between the 10 ethyl esters (loadings); (b) distinction between the samples (scores). 


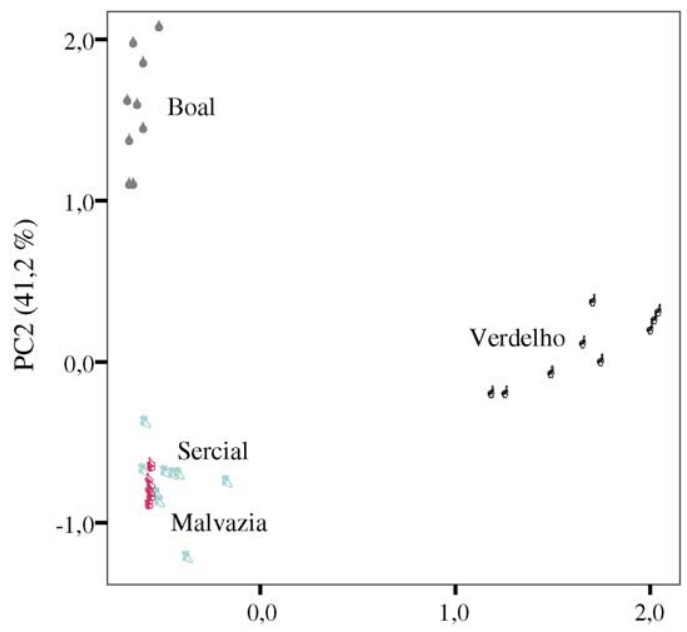

(a)

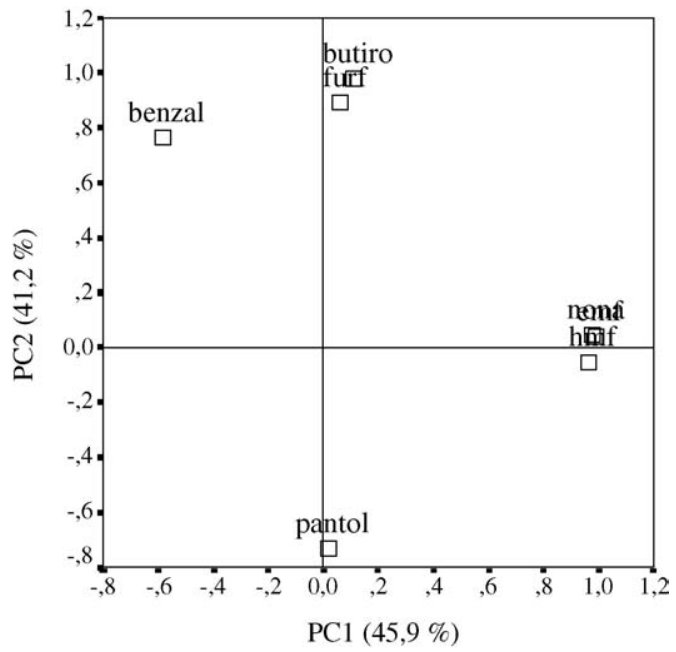

(b)

Fig. 6. PC1 vs. PC2 scatter plot of the main sources of variability between the Madeira wines (a) distinction between the samples (scores); (b) relation between the seven carbonyl compounds (loadings).

classify and differentiate these wines by their variety. Due the great importance of Madeira wines in the Madeira Island economy, this is a good result to find possible adulterations and falsifications.

Table 4

Prediction capacity of Madeira wines discriminant model by cross validation according to wine variety

\begin{tabular}{|c|c|c|c|c|c|c|}
\hline & \multicolumn{5}{|c|}{ Classification results ${ }^{\mathrm{a}, \mathrm{b}}$} & \multirow[t]{3}{*}{ Total } \\
\hline & \multirow[t]{2}{*}{ Casta 1} & \multicolumn{4}{|c|}{ Predicted group membership } & \\
\hline & & VB & VM & VS & VV & \\
\hline \multicolumn{7}{|l|}{ Original } \\
\hline \multirow[t]{5}{*}{ Count } & VB & 7 & 0 & 0 & 0 & 7 \\
\hline & VM & 0 & 7 & 0 & 0 & 7 \\
\hline & VS & 0 & 0 & 7 & 0 & 7 \\
\hline & VV & 0 & 0 & 1 & 6 & 7 \\
\hline & Ungrouped cases & 2 & 2 & 2 & 2 & 8 \\
\hline \multirow[t]{5}{*}{ Percent } & VB & 100.0 & 0 & 0 & 0 & 100.0 \\
\hline & VM & 0 & 100.0 & 0 & 0 & 100.0 \\
\hline & VS & 0 & 0 & 100.0 & 0 & 100.0 \\
\hline & VV & 0 & 0 & 14.3 & 85.7 & 100.0 \\
\hline & Ungrouped cases & 25.0 & 25.0 & 25.0 & 25.0 & 100.0 \\
\hline \multicolumn{7}{|c|}{ Cross-validated $^{c}$} \\
\hline \multirow[t]{4}{*}{ Count } & VB & 7 & 0 & 0 & 0 & 7 \\
\hline & VM & 0 & 7 & 0 & 0 & 7 \\
\hline & VS & 1 & 0 & 6 & 0 & 7 \\
\hline & VV & 0 & 0 & 0 & 7 & 7 \\
\hline \multirow[t]{4}{*}{ Percent } & VB & 100.0 & 0 & 0 & 0 & 100.0 \\
\hline & VM & 0 & 100.0 & 0 & 0 & 100.0 \\
\hline & VS & 14.3 & 0 & 85.7 & 0 & 100.0 \\
\hline & VV & 0 & 0 & 0 & 100.0 & 100.0 \\
\hline
\end{tabular}

VB: Boal wine; VM: Malvazia wine; VS: Sercial wine and VV: Verdelho wine.

a $96.4 \%$ of original grouped cases correctly classified.

b $96.4 \%$ of cross-validated grouped cases correctly classified.

${ }^{\mathrm{c}}$ Cross validation is done only for those cases in the analysis. In cross validation, each case is classified by the functions derived from all cases other than that case.

\section{Summary and conclusions}

HS-SPME/GC-MS is a fast and useful method for isolation and quantification volatile compounds in wines allowing a rapid screening of aroma compounds in wines of different varieties.

Data processing through univariate analysis of variance (Anova) and multivariate analysis (PCA and SLDA) allow good differentiation, classification and prediction models for Madeira wines according to grape varieties. All chemical groups investigated achieved a good separation according to variety, but higher alcohols and ethyl esters seem to be the most important groups for the characterization of Madeira wines.

The variables most correlated with Boal wines are: benzyl alcohol $(0.98 ;-0.12),(E)$-hex-3-en-1-ol $(0.92$; $-0.18)$, benzaldehyde $(-0.41 ; 0.89)$ and $(Z)$-hex2-en-1-ol $(0.83 ;-0.38)$. Ethyl octadecanoate $(0.95$; 0.23), (Z)-hex-3-en-1-ol (-0.32; 0.92), benzoic acid $(0.91 ; 0.33)$, ethyl benzeneacetate $(0.88 ;-0.32)$ and in minor extent ethyl hexadecanoate $(0.86 ; 0.31)$, 2-hydroxybenzenepropionic acid $(0.85 ; 0.43)$, 2-ethylhexanoic acid $(0.36 ; 0.85)$ and diethyl succinate $(0.84$; -0.51) are strongly associated to Malvazia wines. 2Methylpropan-1-ol $(-0.83 ;-0.26)$ is the variable most related with Sercial wines. Verdelho wines are most associated with 5-(ethoxymethyl)furfural $(0.99 ; 0.04)$, nonanone $(0.98 ; 0.05)$, cis-9-ethyldecenoate $(0.11 ; 0.97)$, 5-(hydroxymethyl)furfural $(0.96 ;-0.05)$, ethyl hexanoate $(0.19 ; 0.95)$, propionic acid $(0.91 ;-0.10)$, octanoic acid $(-0.89 ; 0.01)$ 2-methylpropan-1-ol $(-0.83 ;-0.26)$ and hexanoic acid $(-0.78 ; 0.43)$.

Harvest years showed to have no relevant effects on the differentiation of the wines. Stepwise LDA showed to be a good classification method improving the results of the statistical analysis. 


\section{Acknowledgments}

We gratefully acknowledge the Instituto do Vinho da Madeira and Madeira Wine Company for the supply of wine samples, CQM (Madeira Research Chemistry Centre) for the technical support and PRODEP (4/5.3/PRODEP/2000) for financial support.

\section{References}

[1] R.F. Simpson, G.C. Miller, Vitis 22 (1983) 51.

[2] J.S. Câmara, M.A. Alves, J.C. Marques, A.C. Silva Ferreira, Anal. Bioanal. Chem. 373 (2003) 1221.

[3] A.C. Silva Ferreira, A. Bertrand, Enologie 95, in: $5^{\text {e }}$ Symposium International d'œnologie, Bordeaux, Lavoisier, Tec \& Doc, Paris, 1996, p. 520.

[4] R.F. Simpson, J. Sci. Food Agric. 28 (1980) 214.

[5] J.S. Câmara, P. Herbert, J.C. Marques, M.A. Alves, Proceedings of the 3th Symposium In Vino Analytica Scientia, Aveiro, Portugal, 2003.

[6] A. Rapp, H. Mandery, Experientia 42 (1986) 873.

[7] S.P. Arrhenius, L. McCloskey, M. Sylvan, J. Agric. Food Chem. 44 (1996) 1085.

[8] R. Baumes, R. Cordonnier, S. Nitz, F. Drawert, J. Sci. Food Agric. 37 (1986) 927.

[9] A. Rapp, Fresenius J. Anal. Chem. 337 (1978) 777.

[10] I. Moret, G. Scarponi, P. Cescon, J. Agric. Food Chem. 42 (1994) 1143.

[11] V. Ferreira, P. Fernandez, C. Peña, ${ }^{a}$ Escudero, J. Cacho, J. Sci. Food Agric. 67 (1995) 381.

[12] A.C. Noble, R.A. Flath, R.R. Forrey, J. Agric. Food Chem. 28 (1980) 346.

[13] W.O. Kwan, B.R. Kowalski, J. Agric. Food Chem. 28 (1980) 356.

[14] C.M. García-Jares, M.S. García-Martin, N. Carro-Mariño, R. CelaTorrijos, J. Agric. Food Chem. 43 (1995) 175.

[15] M.A. Alves, Ph.D. Thesis, Faculdade de Engenharia da Universidade do Porto, 1992.

[16] P. Guedes de Pinho, Thèse de Doctorat ( $n^{\circ}$ 308) de l'Université Victor Segalen Bordeaux 2, 1994.
[17] M.P. Day, B.L. Zhang, G.J. Martin, J. Food Sci. Agric. 67 (1995) 113.

[18] K. Wada, J. Shibamoto, J. Agric. Food Chem. 45 (1997) 4362.

[19] V. Ferreira, A. Rapp, J.F. Cacho, H. Hastrich, I. Yavas, J. Agric. Food Chem. 41 (1993) 1413.

[20] J.M. Nuñez, H. Bemelmans, J. Chromatogr. 294 (1984) 361.

[21] R. López, M. Aznar, J.F. Cacho, V. Ferreira, J. Chromatogr. A 966 (2002) 166.

[22] Y. Zhou, R. Riesen, C.S. Gilpin, J. Agric. Food Chem. 44 (1996) 818.

[23] G.P. Blanch, G. Reglero, M. Herraiz, J. Agric. Food Chem. 43 (1995) 1251.

[24] A. Razungles, H. El, R. Tarhi, Y.Z. Baumes, Y.Z. Günata, C. Tapiero, C.L. Bayonove, Sci. Aliments 14 (1994) 725.

[25] C. Cocito, G. Gaetano, C. Delfini, Food Chem. 52 (1995) 311.

[26] R. Eisert, J. Pawliszyn, Crit. Rev. Anal. Chem. 27 (1997) 103

[27] C.L. Arthur, J. Pawliszyn, Anal. Chem. 62 (1990) 2145.

[28] M. Aznar, R. López, J.F. Cacho, J.V. Ferreira, J. Agric. Food Chem. 51 (2003) 2700.

[29] R. López, N. Ortín, J.P. Pérez-Trujillo, J.F. Cacho, V. Ferreira, J. Agric. Food Chem. 51 (2003) 3419.

[30] J.S. Câmara, P. Herbert, J.C. Marques, M.A. Alves, Oenologie 2003, 7e Symposium International d'Oenologie. Editions Tec \& Doc, 2003, p. 413.

[31] J.S. Câmara, J.C. Marques, M.A. Alves, Adv. Mass Spectrom. 15 (2001) 943.

[32] J.S. Câmara, P. Herbert, J.C. Marques, M.A. Alves, Anal. Chim. Acta 513 (2004) 203

[33] J.J. Bencomo-Rodríguez, J.E. Conde, M.A. Rodríguez-Delgado, F. García-Montelongo, J.P. Pérez-Trujillo, J. Chromatogr. A 963 (2002) 213

[34] T. Tominaga, M.-L. Murat, D. Dubourdieu, J. Agric. Food Chem. 46 (1998) 1044

[35] José S. Câmara, M. Arminda Alves, José C. Marques, Anal. Chim. Acta (2005) in press.

[36] De la Calle Garcia, S. Magnaghi, M. Reichenbacker, K. Danzer, J. High Resolut. Chromatogr. 19 (1996) 257.

[37] M. Forina, C. Armanino, M. Castino, M. Ubigli, Vitis 25 (1986) 189.

[38] J.J. Powers, E.S. Keith, J. Food Sci. 36 (1968) 207. 